\title{
A novel fast MPPT strategy used for grid-connected residential PV system applied in morocco
}

\author{
Sana Sahbani ${ }^{1}$, Hassane Mahmoudi ${ }^{2}$, Abdennebi Hasnaoui $^{3}$, Mustapha Kchikach $^{4}$, Hanane Benchraa $^{5}$ \\ 1,2,5 Electronics Power and Control Team,Department of Electrical Engineering,Mohammadia School of Engineers, \\ Mohammed V University, Rabat, Morocco \\ ${ }^{1,3,4}$ Electromechanical Department, Higher National School of Mines, Rabat, Morocco
}

\begin{abstract}
Article Info
Article history:

Received Jun 26, 2019

Revised Oct 24, 2019

Accepted Nov 8, 2019

\section{Keywords:}

Maximum power point tracking

Photovoltaic system

Power factor correction

Predictive current control

ABSTRACT

Regardless its significant potential for generating renewable energy, Moroccan government prohibited the injection of production surplus into the low voltage (LV) network because it still lack the implementing decreases, that represents one of the principal challenges for residential self-production in the country. The focus of this paper work is to introduce and analyze a novel fast MPPT strategy applied in an improved grid-connected Residential PV system respecting the current legislative framework in Morocco, which allow to the consumer being an actor in the energy transition towards a low-carbon society by reducing his dependence to the electrical grid and managing his own energy consumption efficiently by a good switching between photovoltaic $(\mathrm{PV})$ source and the grid and therefore making a framework of smart residence management system. The overall system is designed to improve the energy control performance with two techniques: the first one uses a novel high performance controller to track the maximum power point (MPP) of a photovoltaic array under fast irradiation and load changes. Among the advantages of this proposed controller is the stability of its output voltage with fast response speed to the required parameters. The second one uses a Power Factor Correction (PFC) circuit to ensure the power quality regulation in the grid side via a predictive current control method. Finally, the stability of a closed-loop system is simulated and analyzed using commercial software offering sufficient conditions to validate a practical stability and robustness of the proposed overall designed system.
\end{abstract}

This is an open access article under the $\underline{C C B Y-S A}$ license.

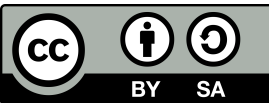

\section{Corresponding Author:}

Sana Sahbani,

Electronics Power and Control Team,

Department of Electrical Engineering, Mohammadia School of Engineers,

Mohammed V University, Rabat, Morocco.

E-mail:sana.sahbani@gmail.com

\section{INTRODUCTION}

As a result of the demographic dynamics added to human development and economic growth, energy consumption in Morocco may lead to an increase average which put the country's natural resources under pressure. In order to confront this challenge, the government has embarked on series of strategies and policies to preserve the exhaustion of its finite natural resources to build a sustainable economy and ensure access to affordable, reliable, sustainable and modern energy for human well-being. According to the IEA [1], the building sector is the largest energy consumer with $25 \%$ share of total energy consumption in Morocco, 
including $18 \%$ for residential area. This energy consumption is expected to increase quickly in the coming years regarding considerable efforts achieved to improve the population's standard of living and prospects with multiples activities: significant building programs development; human development initiative; global rural electrification program for extending access to electricity and the program to improve access to health care and education added to the significant increase and lower prices in the level of households equipment (water heating, refrigeration, ... etc.) [2].

This accelerated consumption trend can only be met by increasing supply and controlling energy consumption, Morocco has taken therefore a global leadership position on climate change mitigation by setting different acts and law of energy efficiency and renewable energy for different sectors and especially for building sector [3] such as: Law 47-09 of November 2011 relating to energy efficiency in residential and commercial buildings. It introduces energy performance ratings for buildings, equipment and appliances. The decree no 2-13-874 of November 2015 is about the Thermal Regulation for Construction in Morocco (TRCM) aiming to optimize heating and cooling necessities in new building by improving the thermal performances of the envelope while improving thermal comfort and reducing the energy consumption. These laws, along with a number of other provisions, are the crucial first steps in the process. The geographical location of Morocco promotes the use of distributed renewable energy systems especially photovoltaic source, that requires further liberalization, particularly increased access to LV network. Then within the implementation framework for the photovoltaic energy development, the law No 58-15 amending and supplementing law No 13-09 on renewable energy was adopted on December 2015. For the opening up of the LV network to decentralized producers, the implementing Decree is still being prepared and until this time, no date had yet been fixed for these provisions to become effective.

With the existing Moroccan regulatory conditions, the individual producer is not allowed to inject excess power produced from his renewable source system in the LV network and cannot become a shareholder in the energy sector by selling surplus production to the grid operator neither can intrinsically reduce his dependence on power generation plants. In the literature, most issues carried out about building integrated photovoltaic (PV) system with bidirectional power flow capability based on inverter circuit for grid synchronization control adding to the maximum power point tracking (MPPT) functions $[4,5,6]$ and the impact of interconnecting PV to grid regarding the standardized power quality, the power grid stability and the safety of equipment [7]. This paper examine an improved model designed for grid connected PV, respecting the actual Moroccan regulatory requirements by keeping only one direction power flow, starting from generator source to households appliances based on a proposed novel Maximum Power Point Tracking (MPPT) technique with higher speed response and stable output voltage waveform of photovoltaic (PV) systems as well as a good load follower. The overall system configuration is designed and analyzed using time scale domain simulation of electrical characteristics, showing the stability of DC link output voltage and load power. The performance of the proposed MPPT control technique and PFC controller circuit are shown and examined.

\section{GRID-CONNECTED PHOTOVOLTAIC SYSTEM}

Figure 1 illustrates the general topology of the designed model; it consists of the main following components: the PV array, which generates power directly from solar radiation, the boost converter, whose switch is operated by the control scheme of the MPPT controller to supply 400V DC distribution networks. Due to the fact that PV array efficiency mainly depends on irradiance and temperature [8], so that the required voltage and current are not fed to the loads every time, therefore the LV grid cover the power difference between load and PV, followed by a single phase diode bridge rectifier, providing constant and one way power flow for DC-link, from the grid to the load according to Moroccan regulatory, and then the boost converter controller, which is applied to provide a power factor correction for rectified current waveform.

\subsection{PV array}

The output power from a single PV cell is relatively small. So the required electrical energy is produced by grouping the PV cells in series and parallel forming the modules. The PV panels are connected together to build up the entire PV array and any desired current voltage characteristics could be generated $[9,10]$. The power-voltage (P-V) and Current-Voltage (I-V) curves of the PV array are illustrated in Figure 2. The manufacturing characteristics measured with the Standard Test Conditions (STC) used in this paper work are given in Table 1. 


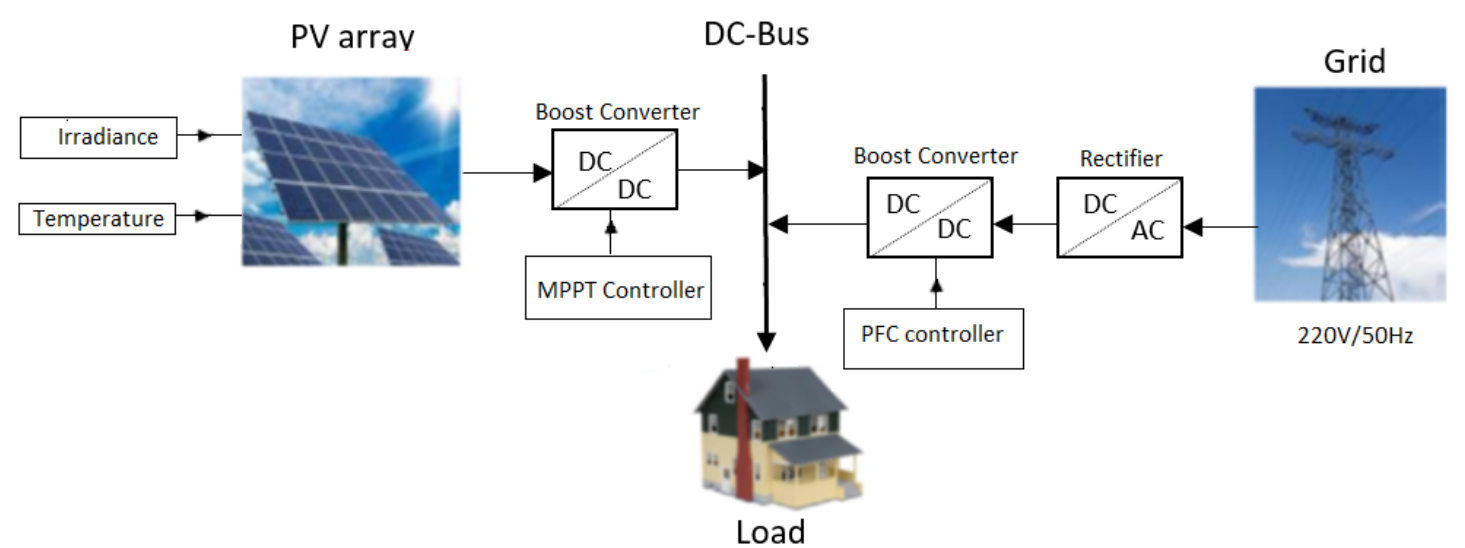

Figure 1. The overall grid connected PV system configuration scheme

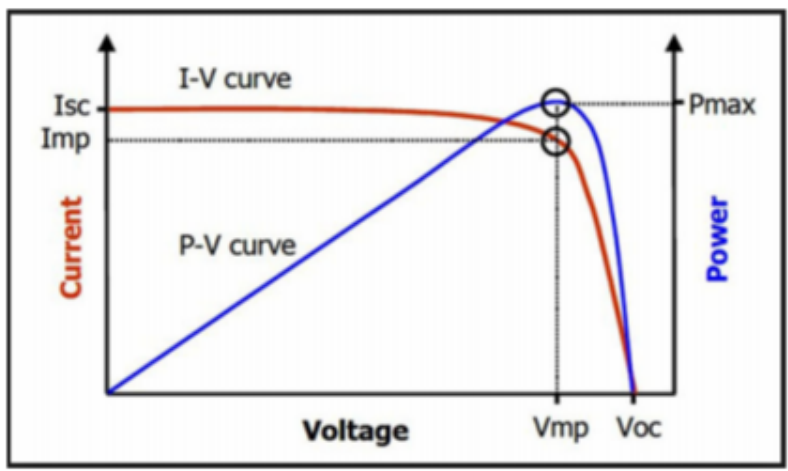

Figure 2. P-V and I-V characteristics of the PV array

Table 1. Specifications of the photovoltaic array

\begin{tabular}{cc}
\hline PV panel parameters & Value \\
\hline Maximum power rating Pmax & $3254,2(\mathrm{~W})$ \\
Short circuit current (Isc) & $12,18(\mathrm{~A})$ \\
Open circuit voltage (Voc) & $341.2(\mathrm{~V})$ \\
Voltage at maximum power point Vmp & $291,6(\mathrm{~V})$ \\
Current at maximum power point Imp & $11.16(\mathrm{~A})$ \\
\hline
\end{tabular}

\subsection{Maximum power point tracking}

The maximum power point shown in Figure 2 varies according to the weather conditions. The basic principle of maximum power point tracking (MPPT) algorithm depends on the exploitation of voltage and current variations caused due to the pulsations of instantaneous power. Analyzing these variations allows us to obtain power gradient expressed in the (1) and evaluate whether the solar PV system operates close to the maximum power point [11]:

$$
\frac{\partial P_{P V}}{\partial V_{P V}}=\frac{\partial\left(V_{P V} I_{P V}\right)}{\partial V_{P V}}=I_{P V}+V_{P V} \frac{\partial I_{P V}}{\partial V_{P V}}
$$

At the maximum power point Pmax, the derivate of power with respect to voltage is equal to zero, which yields to (2):

$$
I_{P V_{M}}=-V_{P V_{M}} \frac{\triangle I_{P V}}{\triangle V_{P V}}
$$


Where $I_{P V_{M}}$ and $V_{P V_{M}}$ are respectively the optimal operation current and voltage of PV array at the condition of maximum power output. In addition, the solar cell exhibits non-linear V-I characteristics as shown in Figure 2 , therefore the MPPT controller must track the maximum power and match the current environmental changes [12].

\subsection{MPPT controller converter}

The MPPT is achieved by using DC-DC Boost converter between PV array and the DC output voltage. It's considered as the heart of MPPT hardware for solar PV applications [13]. From the measured voltage and current, the MPPT algorithm generates the optimal duty ratio to maintain the electrical quantities at values corresponding to the desired parameters [14]. There are many MPPT methods available in the literature; the most widely-used techniques are described in [15], the inconvenient of these techniques is the voltage-ripple emerging during attempts to identify maximum power point. For instance, conventional Perturb Observe (PO) algorithm causes the ripples (oscillations) even if it reaches maximum power point because of its structure [16]. This difficulty increases the power losses and hardens the control actions. Hence, some calculation procedures of conventional PO algorithm was modified and the ripples were corrected [17]. The basic circuit diagram of boost converter is shown in Figure 3, it mainly consists of an Inductor $\mathrm{L}$, capacitor $C_{2}$, controllable semiconductor switch $\mathrm{S}$, diode $D$ and load. $V_{D C}$ is the $400 \mathrm{~V}$-DC distribution network.

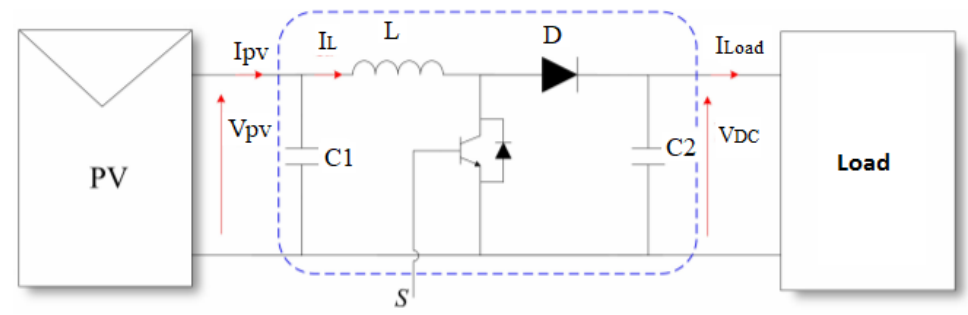

Figure 3. Boost converter circuit

Considering the electrical mesh law of the boost converter circuit shown above, we obtain the following equation:

$$
V_{P V}-L \frac{d I_{P V}}{d t}=\mathrm{d} V_{D C}
$$

Moreover, by calculation the average value of this equation (3) over the switching period interval $[0, T]$, it yields to the following (4):

$$
\frac{1}{T} \int_{0}^{T} V_{P V}-\frac{L}{T} \int_{0}^{T} \frac{d I_{P V}}{d t}=V_{D C} \int_{0}^{T} \mathrm{~d}
$$

Where $V_{\text {ref }}$ is the reference voltage that control directly the switching duty cycle ratio . Thus:

$$
V_{\text {ref }}=\int_{0}^{T} \mathrm{~d}
$$

At $t=T$ : The predicted inductor current will be equal to $I_{r e f}$, which is the internal reference current that will determine the PV output current:

$$
V_{P V_{0}}-\frac{L}{T}\left(I_{P V_{(t=T)}}-I_{P V_{(t=0)}}\right)=V_{D C} V_{r e f}
$$

Therefore, the operation point of the converter by controlling reference voltage calculated in the following (7); the control of $V_{\text {ref }}$ is formulated as a reference current regulation $I_{\text {ref }}$ : 


$$
V_{\text {ref }}=\frac{V_{P V_{0}}-\frac{L}{T}\left(I_{r e f}-I_{P V_{0}}\right)}{V_{D C}}
$$

As explained in the flowchart illustrated in the Figure 4, the reference value that the PV will provide depends on current needed for residential loads. While the load typically varies with unknown way because of the variability of residents activities [18]. The MPPT controller system requires an instantaneous measurement of the load current $I_{\text {Load }}$, which will check whether this measured value is higher than the maximum output current $I_{\max }$ of the PV array as given value, therefore the controller will track the MPP and yields to the following results:

$$
I_{\text {ref }}=I_{P V_{M}}
$$

Where $I_{P V_{M}}$ is the current calculated in the equation (2). If it is not higher than the maximum output current, the predicted reference current Iref that the PV controller will track will be equal to the load current value $I_{\text {Load }}$. Then, the predicted reference voltage $V_{\text {ref }}$ can be calculated from a predicted reference current $\operatorname{Iref}$ as given in the equation (2) and will increase or decrease the PWM duty cycle ratio (D) of the switching device.

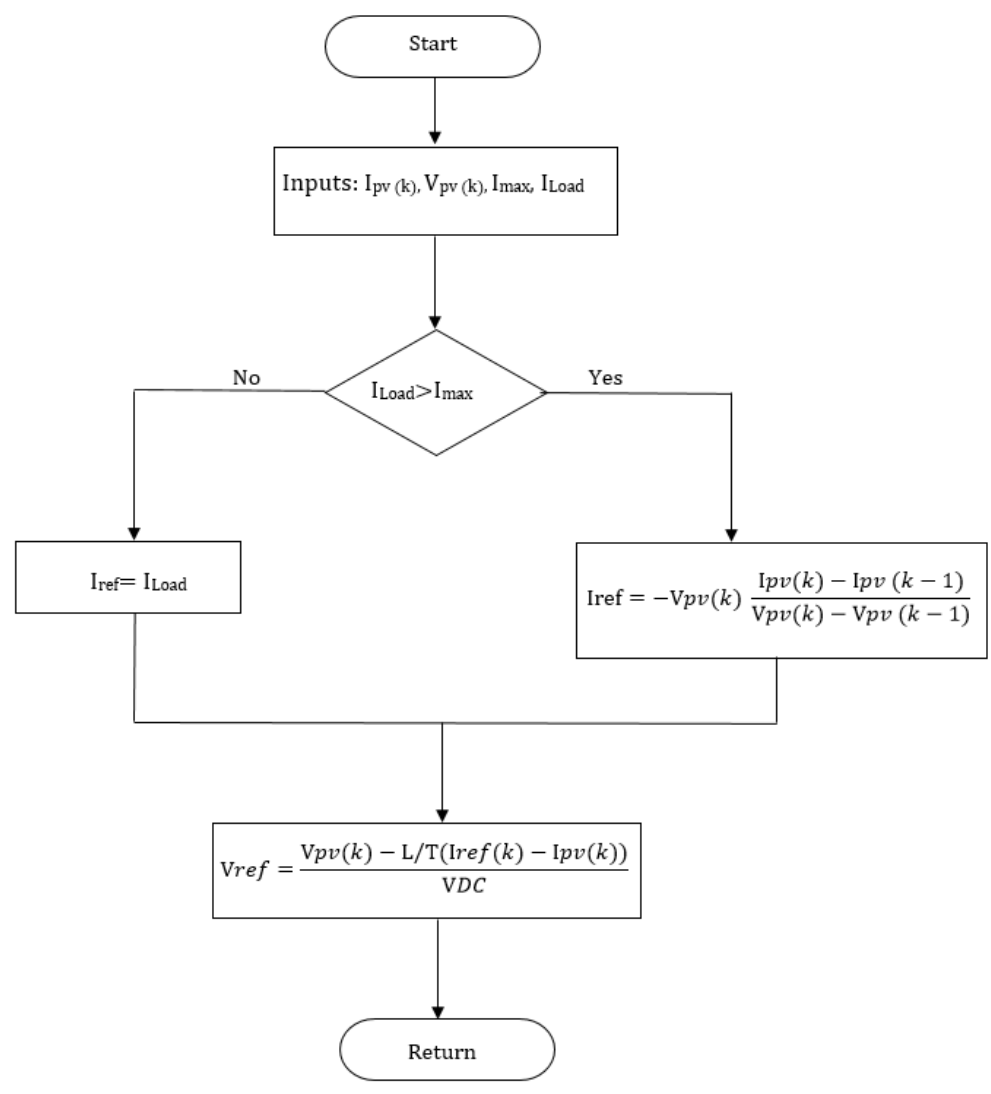

Figure 4. Predictive control algorithm.

\subsection{Grid connected to DC-link utility conversion}

The single-phase diode bridge rectifier used in the proposed configuration is widely used in low voltage distribution systems. However, this classical converter draw non-sinusoidal ac input currents, leading to low power factors and injection of current harmonics into the utility lines [19]. Therefore, it is essential to predict the current harmonic levels produced by these converters [20] by associating them with Power Factor Correction (PFC) stage based on boost topology with a high switching frequency power conversion. The 
major control challenge required of this correcting topology is the capability to follow precisely a rectified sinusoidal current reference. The current control techniques have gained importance in AC-DC conversion used for high performance utilizations, where the fast response and high efficiency are important. Various current control methods have been proposed in PFC circuits, the most commonly studied are : linear control [21], hysteresis control [22] and predictive control [23], a comparative study given by [24] shows that the predictive control offers a good performances regarding to the others proposed control methods in terms of input current harmonic content and power quality. Therefore this technique makes an extremely attractive choice for our proposed model. The circuit scheme considered in the paper work is illustrated in Figure 5. It's realized by cascading single-phase diode bridge rectifier and boost converter with a PFC controller based on predictive current control.

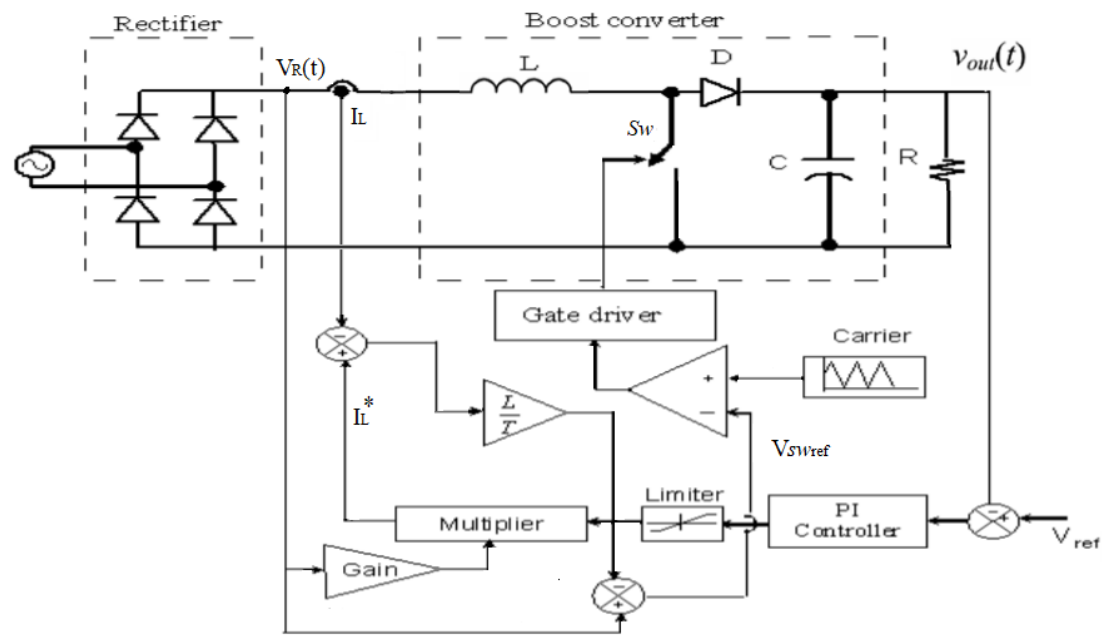

Figure 5. Boost converter with predictive control.

The switch voltage reference $V_{s w_{r e f}}$ at $(k+1)^{t h}$ instant is predicted at $(k)^{t h}$ instant itself for the circuit shown in Figure 5 by means of equation (9):

$$
V_{s w_{r e f}}=V_{R_{(t)}}-\frac{L}{T}\left(i_{L(t)}^{*}-i_{L(t)}\right)
$$

Where:

- $V_{R}:$ Rectified voltage.

- $i_{L}:$ Inductor current.

- $i_{L}^{*}$ : The reference current that the inductor current $i_{L}$ should follow which is proportional to the rectified voltage.

- $T$ : Modulation period (inverse of switching frequency).

As it will be shown in simulation results, this technique makes it possible to obtain good performances such as the stability of the system, precise behavior of the currents, input and output voltage.

\section{OVERALL SYSTEM CONCEPTION}

The overall system design of grid-connected PV using commercial software is given in Figure 6. The grid-connected PV system consists of a $3 \mathrm{~kW}$ PV array connected to a 400V DC-link for supplying power to residential load $R_{D C}$ through a boost converter controlling the power delivered from the PV using a novel MPPT controller. On the right side of the system scheme, the $220 \mathrm{~V}$ AC source provided from single phase grid ensure local supply continuity when there is a lack of irradiation, the delivered power is converted and stepped up to $400 \mathrm{~V}$ DC via diode bridge rectifier associated to the boost converter with a PFC controller. The specifications and the components used in the proposed design are illustrated in Table 2: 


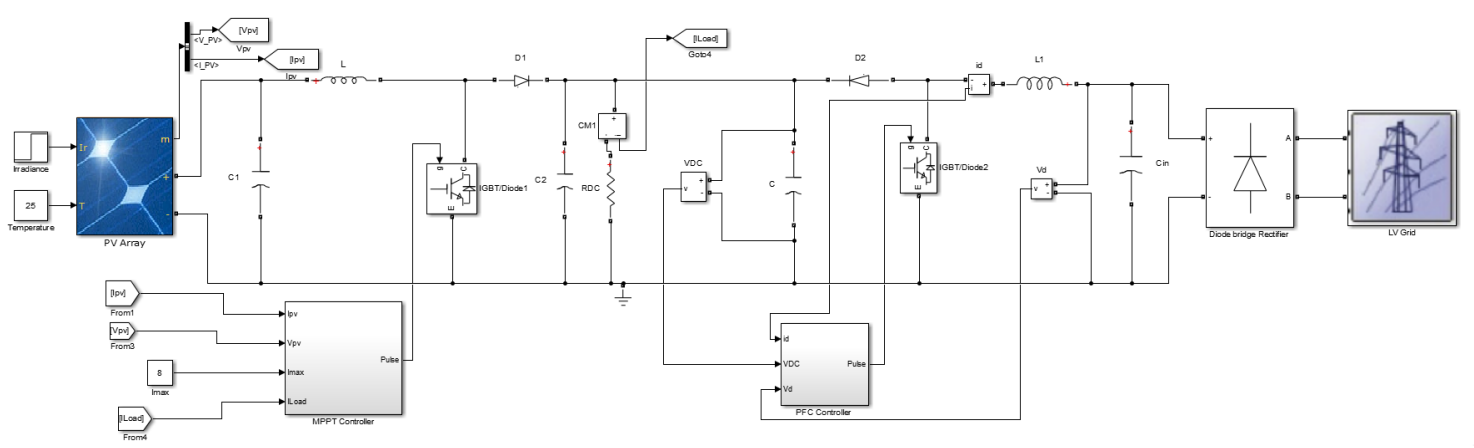

Figure 6. The overall grid connected PV system scheme.

Table 2. Specifications of the circuit components

\begin{tabular}{cc}
\hline Circuit parameters & Value \\
\hline Stray capacitance C1 & $1 \mathrm{mF}$ \\
Boost inductor L & $5 \mathrm{mH}$ \\
DC link capacitance $(\mathrm{C} 2)$ & $10 \mu \mathrm{F}$ \\
DC link Full Load $\mathrm{R}_{D C}$ & $48 \Omega$ \\
DC link Partial Load $\mathrm{R}_{D C}$ & $88 \Omega$ \\
MPPT Boost converter switching frequency & $10 \mathrm{Khz}$ \\
DC link Voltage & $400 \mathrm{~V}$ \\
Grid nominal voltage & $220 \mathrm{Vrms}$ \\
PFC Boost convetrer switching frequency & $10 \mathrm{Khz}$ \\
Boost inductor L1 & $5 \mathrm{mH}$ \\
Stray capacitance Cin & $10 \mathrm{nF}$ \\
Output Capacitor C & $10 \mathrm{mF}$ \\
Time step simulation Ts & $1 \mu \mathrm{s}$ \\
\hline
\end{tabular}

\section{SIMULATION RESULTS AND ANALYSIS}

The aim of these simulations results is to verify the performance of the proposed controllers designed in previous sections as the proposed MPPT strategy performances regarding voltage stability and response speed and the good following of the reference. And also the PFC converter performances in forcing the input current to follow the wave shape of the rectified input voltage added to the automatic switching between grid and PV for providing stable power to the loads when the environmental conditions are changing. Therefore; the system is analyzed for different scenarios considering irradiation and load changes:

\subsection{Overall grid connected system operating with full-load and irradiation change}

The controllers capability is tested with a full residential load under solar irradiation change conditions. As shown by Figure 7; the system was initially subjected to a sun irradiation condition of $500 \mathrm{~W} / \mathrm{m}^{2}$ until the time $t=5 \mathrm{~s}$ when it jump to $1000 \mathrm{~W} / \mathrm{m}^{2}$ (using step change), simultaneously the output current, voltage and power waveforms of the PV array are displayed. It can be seen from the diagram that the power supplied by the PV array varies according to the intensity of the environment's light. At $1000 \mathrm{~W} / \mathrm{m} 2$ of irradiation with full-load condition, the controller is able to track the highest MPP voltage and current values of $290 \mathrm{~V}$ and $11 \mathrm{~A}$, resulting in a power of $3200 \mathrm{~W}$ with the least MPP tracking time equal to $0.02 \mathrm{~s}$ and non-oscillatory response around the MPPT. Once the system reached its steady state, it proves the stability and the velocity of the proposed MPPT strategy.

With the same conditions mentioned above; the DC-link system simulation results with the proposed MPPT controller are shown in Figure 8. it can be seen that despite the decresase of PV Panel power generated at times when irradiation level is weak $\left(500 \mathrm{~W} / \mathrm{m}^{2}\right)$, the response obtained shows the stability of the DC-link output voltage, which is close to $400 \mathrm{~V}$. This voltage value ensures the good switching between AC grid and $\mathrm{PV}$ panel in providing stable power to residential load. 

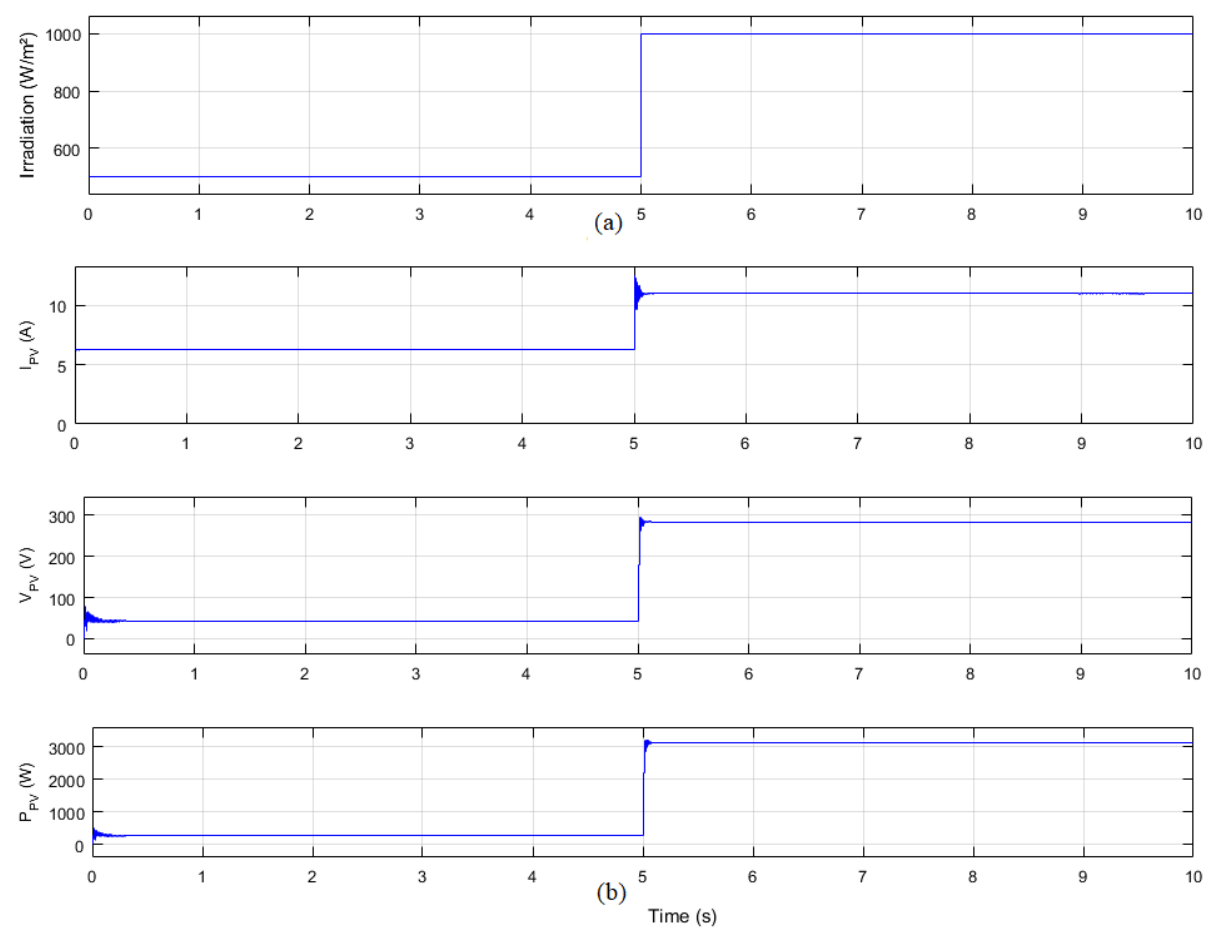

Figure 7. (a) Solar irradiation change, (b) The output current, voltage and power of the PV array for full-load
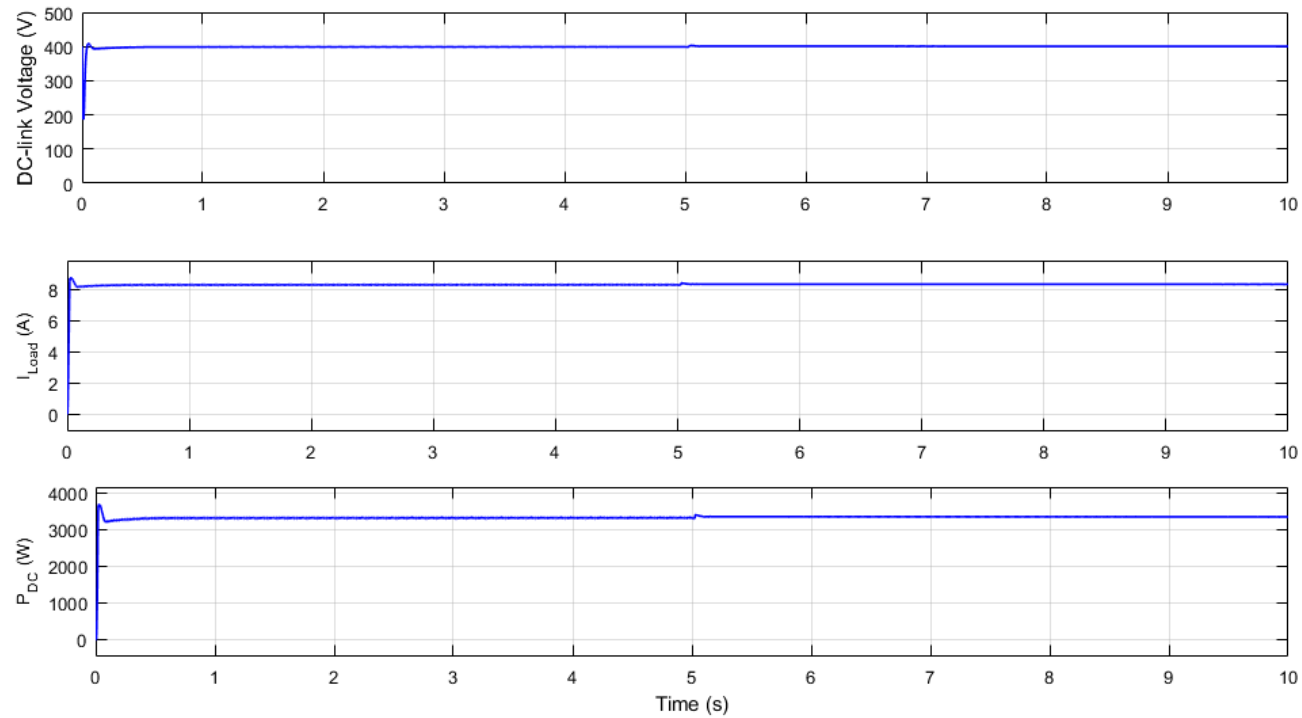

Figure 8. Output voltage, current and power in DC link for full-load

In another hand, from the PFC performances shown in Figure 9, the load is supplied by the AC grid because of the low irradiation level and the resulting waveforms shows that the rectified current follows the rectified voltage wave shape and are in phase, which, explain the good tracking capabilities of the Predictive Current Control method when the irradiation conditions change quickly to the optimal condition of sun irradiation. The device find the maximum power point of the PV panel then the rectified grid current tends to be zero, explaining that in this duration, the electrical grid becomes idle and the power source is switched to the PV generator. 

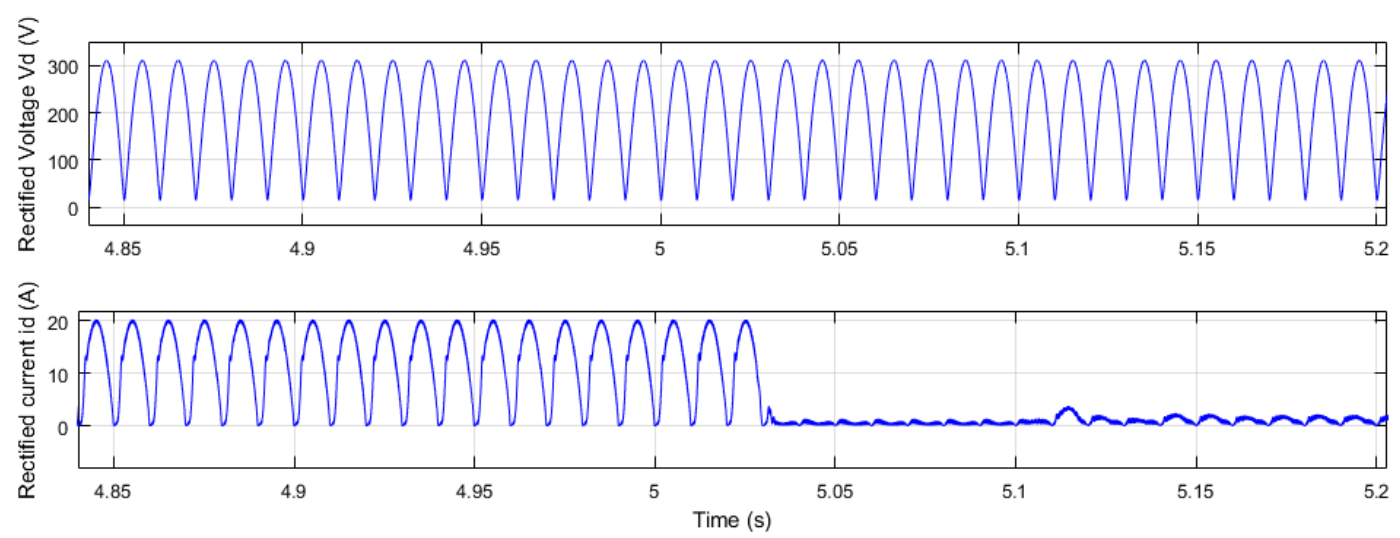

Figure 9. Rectified voltage and current waveforms.

\subsection{Overall grid connected system operating with partial load considering optimal irradiation condi- tion}

As illustrated by Figure 4 in the previous paragraph, the proposed MPPT controller complies with both full load and partial load. With standard test conditions $\left(1000 \mathrm{~W} / \mathrm{m}^{2}\right.$ solar irradiation) we use a partial load of $88 \Omega$, so the needed current for a fixed DC-voltage of $400 \mathrm{~V}$ is $4.5 \mathrm{~A}$, which is smaller than $8 \mathrm{~A}$ the maximum output current of the PV. In Figure 10, the DC load draws a new smaller power value from the PV array (the PV now is not working at MPP as there's nowhere for the excess power to go). Therefore,the MPPT controller will adjust the duty cycle of the converter to meet the required load at constant output voltage, then the PV automatically becomes a load follower and operate at the point where the output power matches the load, in this example the output power is close to $1800 \mathrm{~W}$.
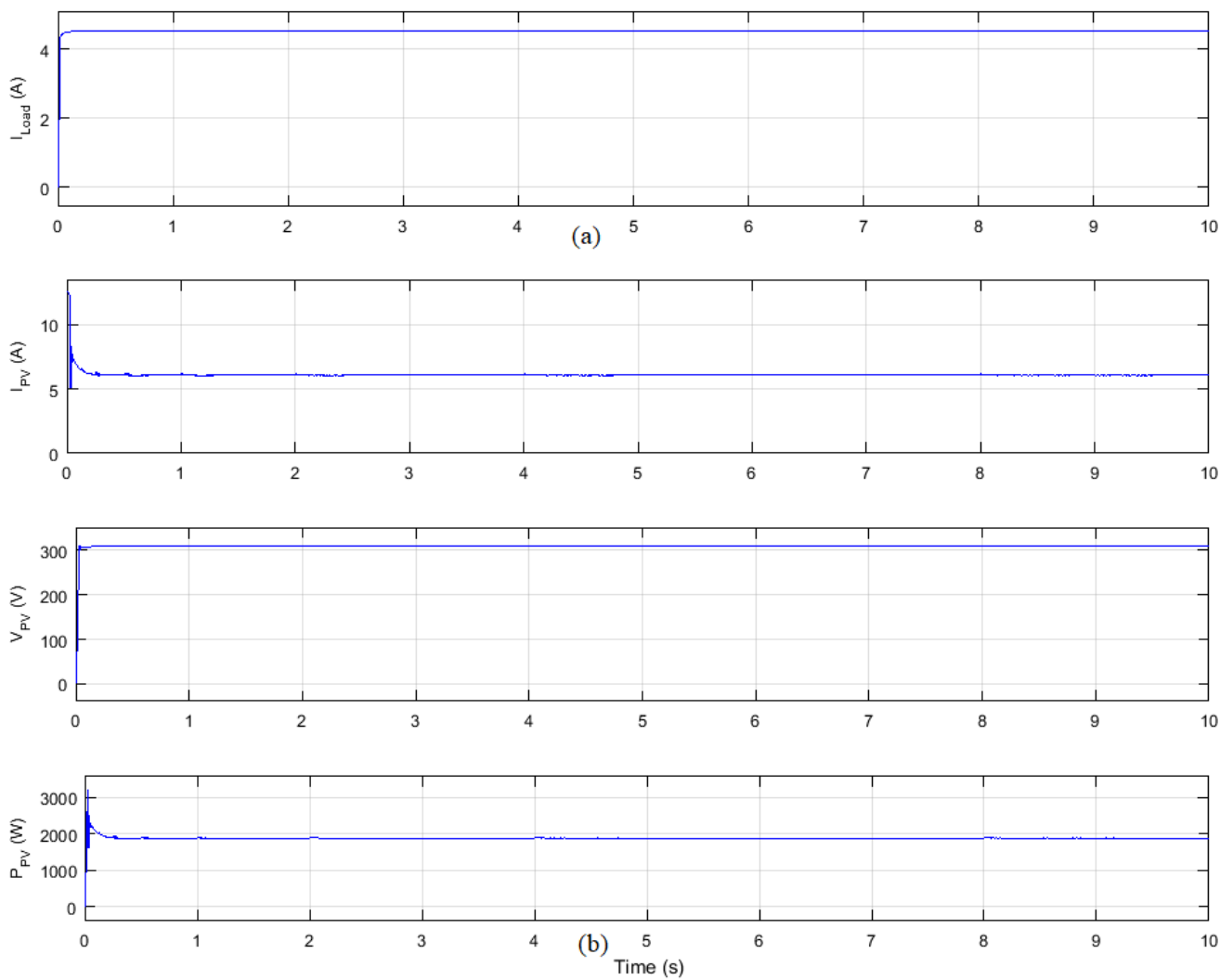

Figure 10. (a) Output current for partial-load,(b)the PV array current, voltage and power. 


\section{CONCLUSION AND PERSPECTIVE}

In this paper, we have developed a circuit design of a single-phase grid connected PV for home energy management system within the Moroccan context of renewable energy integration, that enables users to economies energy consumption and reduce their dependence on fossil fuel. This paper has presented the modeling and control design of two-stage: PV system based on a boost converter with the proposition of a novel MPPT technique, with a constant PV output voltage based on predictive control method, to track even the MPP of a PV or another operating point depending on load change and a single-phase grid connected diode rectifier with PFC controller for regulating the DC link voltage and the rectified current waveform with a good track of the reference. The two stages are connected to a residential load and depending on meteorological conditions they ensure a good switching between them in providing power supplying load. Based on the above analysis of the simulation results, the controllers designed in each stage of this paper offers good performances in term of speed of convergence to the required operating voltage and current parameters added the stability of their waveforms under various atmospheric and operating conditions with minimum tracking time. Hence, this designed system can promote the development of distributed photovoltaic power generation in Morocco and the residential user can forecast his electrical energy consumption and therefore reduce his electrical bill and be an actor in saving the environment.

As a future work, controlling the use of households will be proposed in order to use efficiently the PV generator when we have favorable meteorological conditions by exploiting the Maximum Power Tracking, and use only necessary loads at night. To enhance the reliability and stability of DC-link voltage, the battery system can be added to this model in order to maintain the DC link voltage when occurs a power grid outages.

\section{REFERENCES}

[1] IEA [Online]. availible "www.iea.org."

[2] ONEE National Office of Electricity and Water [Online]. availible "www.onee.org.ma."

[3] The Ministry of Energy, Mines and Sustainable Development [Online]. availible "www.mem.gov.ma."

[4] C. Limsakul, R. Songprakorp, A. Sangswang and P. Parinya, "Impact of photovoltaic grid-connected power fluctuation on system frequency deviation in contiguous power systems," IECON 2015-41st Annual Conference of the IEEE Industrial Electronics Society, P003236-003241, 2015.

[5] A. Chouder, S. Silvestre, N. Sadaoui and L. Rahmani, "Modeling and simulation of a grid connected PV system based on the evaluation of main PV module parameters," Simulation Modelling Practice and TheoryElsevier, vol. 20, no. 1, pp. 46-58, 2012.

[6] F. Blaabjerg, R. Teodorescu, M. Liserre and A. Timbus,"Overview of control and grid synchronization for distributed power generation systems," IEEE Transactions on industrial electronics, vol. 53, no. 5, pp. 1398-1409, 2006.

[7] S. B. Kjaer , J. K. Pedersen and F. Blaabjerg," A review of single-phase grid-connected inverters for photovoltaic modules," IEEE transactions on industry applications, vol. 41, no. 5, pp. 1292-1306, 2005.

[8] B. V. Chikate and Y. Sadawarte, "The factors affecting the performance of solar cell," International journal of computer applications, vol. 1, no. 1, pp. 0975-8887, 2015.

[9] E. Koutroulis and F. Blaabjerg, "A new technique for tracking the global maximum power point of PV arrays operating under partial-shading conditions," IEEE Journal of Photovoltaics, vol. 2, no. 2, pp. 184190, 2012.

[10] D. La Manna, V. L. Vigni, E. R.Sanseverino, V. Di Dio and P. Romano, "Reconfigurable electrical interconnection strategies for photovoltaic arrays: A review," Renewable and Sustainable Energy Reviews, vol. 33, pp. 412-426, 2014.

[11] D. Casadei, G. Grandi and C. Rossi, "Single-phase single-stage photovoltaic generation system based on a ripple correlation control maximum power point tracking," IEEE Transactions on Energy Conversion, vol. 21, no. 2, pp. 562-568, 2006.

[12] C. L. Kuo, C. H. Lin,, H. T. Yau and J. L. Chen, "Using self-synchronization error dynamics formulation based controller for maximum photovoltaic power tracking in micro-grid systems," IEEE Journal on Emerging and Selected Topics in Circuits and Systems, vol. 3, no. 3, pp. 459-467, 2013.

[13] D. Gaikwad, M. Chavan and M. Gaikwad, "Hardware implementation of dc-dc converter for mppt in pv applications," IEEE Global Conference on Wireless Computing and Networking Proceedings, pp. 16-20, 2014. 
[14] B. Bendib, H. Belmili and F. Krim, "A survey of the most used MPPT methods: Conventional and advanced algorithms applied for photovoltaic systems," Renewable and Sustainable Energy Reviews, vol. 45, pp. 637-648. 2015.

[15] A. Dolara, R. Faranda and S. Leva, "Energy comparison of seven MPPT techniques for PV systems," Journal of Electromagnetic Analysis and Applications, vol. 1, no. 3, pp. 152, 2009.

[16] A. Pandey, N. Dasgupta and A. K. Mukerjee, "A Simple-Sensor MPPT Solution," IEEE Transactions on Power Electronics, vol. 22, no. 2, pp. 698-700, 2007.

[17] M. A. Özçelik, "Effect of improving perturb and observe MPPT algoritm on AC grid connected PV systems," Istanbul University-Journal of Electrical Electronics Engineering, vol. 16, no. 2, pp. 30253032, 2016.

[18] F. Issi and O. Kaplan, 'The Determination of Load Profiles and Power Consumptions of Home Appliances," Energies, vol. 11, no. 3, pp. 607, 2018.

[19] Z. Yang and P. C. Sen, "Recent developments in high power factor switch-mode converters," In Conference Proceedings. IEEE Canadian Conference on Electrical and Computer Engineering Cat, vol. 2, pp. 477-480, 1998.

[20] B. R. Lin and H. H. Lu, "Single-phase power-factor-correction AC/DC converters with three PWM control schemes," IEEE Transactions on Aerospace and Electronic Systems, vol. 36, no. 1, pp. 189-200, 2000.

[21] V. M. Rao, A. K.Jain, K. K. Reddy and A. Behal, "Experimental comparison of digital implementations of single-phase PFC controllers," IEEE Transactions on industrial electronics, vol. 55, no. 1, pp. 67-78, 2008.

[22] K. Kayisli, S. Tuncer and M. Poyraz, "Hysteresis control of a boost pfc converter circuit," In Power Electronics Specialists Conference. Annual IEEE, pp. 800-807, 2006.

[23] W.Zhang, G. Feng, Y. F. Liu and B. Wu, "A digital power factor correction (PFC) control strategy optimized for DSP," IEEE Transactions on Power Electronics, vol. 19, no. 6, pp. 1474-1485, 2004.

[24] M. Perez, J. Rodriguez A. Coccia "Predictive current control in a single phase PFC boost rectifier," IEEE International Conference on Industrial Technology, pp. 1-6, 2009. 